\section{Sorria, você está sendo filmado: o telejornalismo apócrifo e o efeito de tragicidade das imagens de videovigilância}

\author{
Smile, you are on camera: the \\ apocryphal television news bulletin \\ and the tragic effect of video \\ surveillance images
}

Ana Paula Goulart de Andrade ${ }^{[a]}$, Sandro Tôrres de Azevedo ${ }^{[b]}$

\section{Resumo}

A proposta deste artigo é analisar os efeitos de sentido advindos de imagens capturadas especificamente por videovigilância e utilizadas na narrativa construída pelos telejornais locais e nacionais, dando continuidade à pesquisa sobre o "telejornalismo apócrifo", empreendida pelos autores desde 2010. Pretende-se aqui questionar os critérios de noticiabilidade a partir da escolha de enquadramentos e tratamentos próprios do Jornalismo Televisivo que remetam à ideia de tragicidade. Busca-se explorar fundamentos teóricos relacionados à questão do discurso midiático no cenário contemporâneo (mormente a conceitos dados por autores de
Jornalista, mestranda em Comunicação pela Pontifícia Universidade Católica do Rio de Janeiro (PUC-Rio), professora da Universidade Estácio de Sá (Unesa), Niterói, RJ - Brasil, e-mail: goulartdeandrade@gmail.com

[b] Publicitário, doutorando em Estudos de Linguagem pela Universidade Federal Fluminense (UFF), professor dos cursos de Jornalismo e de Publicidade e Propaganda da Universidade Veiga de Almeida (UVA), Faculdades Integradas Hélio Alonso (Facha) e Universidade Estácio de Sá (Unesa), Rio de Janeiro, RJ - Brasil, e-mail: san-drotorres.com@gmail.com

Palavras-chave: Telejornalismo. Telejornalismo apócrifo. Videovigilância. Discurso. Semiótica. 
áreas conexas à Comunicação, como Michel Foucault, Mauro Wolf, Peter Berger e Thomas Luckman, Erving Goffman, entre outros), para se estabelecer uma reflexão sobre o objeto de pesquisa e sobre os objetos de análise elencados. Ainda para alcançar esse objetivo, utiliza-se o ferramental teórico da Semiótica Discursiva Francesa (greimasiana), especialmente sob a visão de Eric Landowski. Um comercial da marca Coca-cola e uma matéria telejornalística baseados em imagens de videovigilância servirão de artifícios para o estudo de caso e verificação das proposições relacionadas ao universo discursivo que figura atualmente nas práticas telejornalísticas.

\section{Abstract}

The purpose of this paper is to analyze the meaning effects coming from surveillance camera images used by local and national news bulletin to build a narrative, carrying on the research on "apocryphal television news bulletin" that has been developed by the authors since 2010. It is intended to question the newsworthiness criteria through the selection of frames and the particular Broadcast Journalism process which are related to the tragedy idea. It is purposed to explore theoretical fundaments related to media discourse in contemporary scenario (mainly concepts created by authors in Communications related fields, such as Michel Foucault, Mauro Wolf, Peter Berger and Thomas Luckman, Erving Goffman, among others), as well as French Discourse Semiotics references (gremasian), specially under Eric Landowski perspective, to establish a reflection on both research and analyzed objects. An advertising video of Coca-Cola and a television news bulletin story based on surveillance camera images will be studied in this paper as references and for checking the suggestions related to the discourse universe in televi-sion news bulletin practices in these days.
Keywords: Television news bulletin. Apocryphal television news bulletin. Video surveillance images. Discourse. Semiotics. 


\section{Introdução}

Este trabalho visa à continuidade das pesquisas em torno do conceito de "telejornalismo apócrifo", sobre o qual os autores têm formulado proposições nos últimos dois anos e proposto discussões nos fóruns pertinentes ao jornalismo em âmbito nacional. O conceito supracitado se relaciona ao fato de que o noticiário televisivo está marcado pela presença corriqueira de imagens capturadas por instâncias externas às empresas jornalísticas (por causa do impacto da atual popularização dos dispositivos digitais e de seus efeitos). Aqui são abordadas com mais ênfase as questões que envolvem as imagens produzidas por câmeras de vigilância utilizadas na produção de matérias telejornalísticas. Em princípio, busca-se traçar constructos comprometidos com a relação entre as imagens de videovigilância e a narrativa construída pelos telejornais.

Como mero recurso instrumental, recorre-se, de início, a um comercial de televisão para encetar um processo reflexivo que traga as imagens capturadas por câmeras de vigilância para o centro das discussões que se propõem sobre o telejornalismo, seus discursos e práticas. Nota-se, de maneira geral, que a temática que inequivocamente comparece no uso de imagens apócrifas (ANDRADE, 2010; ANDRADE; AZEVEDO, 2010) se filia às cenas da violência e do terror, sempre conferindo tragicidade à narrativa e cobrindo discursos trágicos que compõem os valores-notícia mais banais na TV brasileira contemporânea.

Propõe-se, aqui, além da problematização do assunto, um estudo de caso sobre uma reportagem telejornalística, exibida no Jornal Hoje (TV Globo), sobre o assassinato de uma professora aposentada em sua casa no interior de Minas Gerais.

Nessa esteira, recorre-se a: conceitos da Semiótica Francesa, especificamente a Landowski (2002); princípios teóricos sobre o discurso propostos por Foucault (1987, 2010); teorias sobre os critérios de noticiabilidade e construção da notícia dadas por Mauro Wolf (2003) e Berger e Luckman (2003); além do conceito de representação de Goffman (2002), entre outros.

\section{Videovigilância: para o bem e para o mal}

Na melhor expressão daquilo que se pode considerar criatividade publicitária, um comercial desenvolvido pela produtora Landia para a marca 
Coca-cola ${ }^{1}$ para veiculação na América Latina ${ }^{2}$ mostra uma sequência de imagens capturadas por câmeras de segurança. Ao contrário do que se pode esperar, as imagens são, na verdade, flagrantes de gestos bons, atitudes louváveis e, enfim, cenas positivas e inspiradoras. Seguindo o conceito da campanha sintetizado no slogan "Coca-cola: abra a felicidade", o comercial se utiliza de uma técnica bastante conhecida no meio da propaganda, a qual consiste no impacto do público espectador a partir da demonstração do não esperado, do surpreendente.

As cenas felizes são cobertas pela música Give a Little Bit, de Roger Hodgson (Supertramp), o que potencializa a perspectiva "bondosa" do olhar proposto pelo anunciante para as imagens de videovigilância. Ainda, todas as situações são acompanhadas de uma legenda que ratifica a proposição ideológica do conceito da propaganda:

As câmaras de segurança ao redor do mundo / Também capturam / Pessoas roubando beijos, /Viciados em música, / Soldados inofensivos,/ "Pegadores" de carteiras honestos / E "atravessadores" de batata frita. / Ataques de amizade, / Amor / E bondade. / Gangues amigáveis, / Bombeiros inesperados, / Rebeldes com uma causa / E guerreiros pacíficos. / Um monte de gente louca / E alguns poucos heróis loucos. / Vamos olhar para o mundo de um jeito um pouco diferente. /Coca-cola: abra a felicidade ${ }^{3}$.

Em Presenças do outro, Landowski (2002, p. 125-163) discute de que forma a publicidade como um todo, por meio de seus discursos, construiu no imaginário social um "universo" próprio de significação; nesse universo, as peças publicitárias, de maneira geral, puderam, independente do meio utilizado, época de veiculação ou mesmo marca anunciante, compor uma narrativa única, sendo cada uma em particular um pedaço que se encaixa com razoável facilidade nas peças que the precedem ou sucedem. $O$ resultado dessa imensa articulação ad infinitum de percepções que eclodem das enunciações publicitárias, pode-se afirmar, é uma "ambiência onírica" (BARRETO, 2004, p. 193), comprometida com uma visão paradisíaca e ideal de mundo. Sob esse olhar, tudo é perfeito e ajustado à felicidade, à alegria e à beleza.

1 COCA-COLA Security Cameras. Disponível em: <http://www.youtube.com/watch?v=auNSrt-QOhw>. Acesso em: 28 jul. 2012.

2 Segundo o site Comunique9. Disponível em: <http://www.comunique9.com.br/2012/06/ coca-cola-came-ra-de-seguranca.html>. Acesso em: 28 jul. 2012.

3 Livre tradução dos autores. 
Se o tema do anúncio não tratar especificamente de qualquer coisa ruim, a cena toda estará absolutamente purificada de todo mal, em qualquer quantidade: nada de complexo de Édipo, luta de classes, opressão, poluição, uma unha partida, uma mosca no ombro dela - nada disso ocorre no país do anunciante, homens e mulheres elevados à quintessência da perfeição, graças à presença mágica e protetora do produto (BARRETO, 2004, p. 193).

O efeito de sentido dado pela propaganda da Coca-cola mencionada anteriormente, portanto, se vale de uma desconexão/contraposição entre um contrato simbólico de ideias positivas aneladas à publicidade de marcas, de um lado, e outro contrato simbólico de ideias negativas que estão associadas às imagens de videovigilância, de outro.

As observações acerca desse comercial empreendidas até agora servem de artifício para a proposição deste artigo que retoma a pesquisa sobre o "telejornalismo apócrifo" (ANDRADE, 2010; ANDRADE; AZEVEDO, 2010, 2011) e modela aqui as hipóteses deste trabalho. Primeiro, as imagens de câmeras de vigilância, tal como ocorre com as imagens na publicidade (na referida perspectiva de Landowski), seriam partes de uma mesma narrativa geral, que corporificam, enfim, um enredo dado pela circulação dessas imagens em telejornais. Em segundo lugar, aí sim muito diferente da situação na publicidade, as imagens de videovigilância suscitam olhares acostumados com enquadramentos de temas ligados ao terror, à violência, ao crime, ao flagrante do pernicioso e do abominável. Assim, o universo simbólico do telejornalismo apócrifo especificamente construído por imagens de câmeras de vigilância é constituído por um campo de presença (LANDOWSKI, 2002) em que os sujeitos e objetos (sujeitos-sujeitos, sujeitos-objetos e objetos-objetos) estão necessariamente em disjunção e a oclusão da audiência está sempre fadada à expectativa de espetacularização do trágico.

Ainda sobre essas hipóteses, cabe a formulação de diversos problemas: por que não figuram na cena telejornalística as imagens que revelam heróis ou confirmam atos de boa-vontade? Quanto dos flagrantes das câmeras de vigilância corrobora e ratifica um agendamento excessivamente comprometido com a audiência dada pela exibição do trágico e do grotesco? E, por isso, quanto as imagens de videovigilância são interessantes economicamente para as empresas telejornalísticas, que preenchem o conteúdo da programação, dispensando parte do trabalho da mão de obra jornalística, dado que tratam-se de imagens cedidas? 
Enfim, quanto a presença de imagens dessa natureza conforma o público expectador a acostumar seu olhar para esperar por mensagens compromissadas com temáticas trágicas, o que realimenta a conveniência de reincidência dessas imagens, criando uma espiral ascendente infinita?

Obviamente, este trabalho, a princípio, visa muito mais elencar as questões relacionadas com o tema, e trazê-las para o centro do debate acadêmico no âmbito do Jornalismo, do que ter a pretensão de apontar as respostas definitivas para a problemática.

\section{O efeito de tragicidade}

Os olhos não veem, o coração não sente e as imagens apócrifas não mostram. E o contrário também. $O$ que precisa ser dito é que há uma séria demanda por imagens de flagrantes que complementem a programação dos telejornais. Constantemente, veículos jornalísticos buscam esses materiais visando sua utilização para narrativas telejornalísticas, sendo que, em sua maioria, são baseadas em fatos nos quais está embutida a ideia do risco (VAZ, 1999, p. 159-175).

Como Paulo Vaz (1999) afirma, a questão que se coloca entre a mídia e a divulgação de situações limítrofes de tragicidade se organiza a partir da legitimação que a audiência confere ao veículo que adverte da existência dos riscos e propõe os meios para contorná-los. É nesse sentido que se inicia a cadeia viciada em que cada vez mais imagens de videovigilância carregadas de cenas "fortes" (no nível do "horror") ocupam o espaço dos telejornais, tanto quanto, cada vez mais a audiência demanda esse tipo de narrativa, como dito acima, formando uma espiral ascendente tendendo ao infinito. A lógica que se espera é a do aumento gradativo e constante de elementos narrativos audiovisuais cedidos pelo cidadão comum, pela polícia local, pelas câmeras de controle de tráfego etc., a serem apenas cobertas por locuções em off ou mesmo por ancoragem do apresentador ao vivo.

De certa forma, esse quadro inspira a preocupação com um possível esvaziamento do motor jornalístico, tendendo à decadência dos critérios de noticiabilidade, tanto quanto, por outro lado, não se pode divisar uma forma de interrupção (ou freio, que seja) da ansiedade do telespectador por esse tipo de conteúdo. Esse comportamento da sociedade contemporânea requer novos olhares sobre o jogo social do qual o Telejornalismo participa, na medida em que, ao enquadrar um determinado tema de tragédia, legitima um discurso e o traduz como assunto 
para o telespectador, apostando na continuidade de um produto televisivo com garantia de audiência. Assim é que se estabelecem olhos viciados para com o tipo de imagem que se alude neste trabalho.

A questão do agendamento dos acontecimentos, pontuados pelas imagens apócrifas oriundas de videovigilância, legitimadas pelos veículos de comunicação, naturaliza o olhar através do telejornalismo apócrifo, que se sedimenta a partir das novas tecnologias e contribui, portanto, para a construção de novos modos de interpretação. É aqui que se torna muito importante ressaltar que os olhos já estão acostumados a verem nesse produto o flagrante delineado pela ótica do medo, do até esperado (na medida em que a leitura já é predeterminada); desse modo, a construção do discurso em ato (LANDOWSKI, 2002) - a exibição da matéria final - enuncia um efeito de tragicidade que funda a natureza do universo simbólico a ser resgatado pela audiência na hora de decodificar a mensagem que subjaz à imagem de uma câmera de vigilância.

Esse efeito, então, perpassa de uma matéria a outra, construindo um campo semântico próprio para as narrativas que incluem imagens de videovigilância, de modo que sempre que esse tipo de imagem aparece na cena telejornalística, a perspectiva do obscuro, do abominável - do trágico e do risco - são resgatados pelo telespectador de seu repertório constituído. É essa assertiva, inclusive, que garante o efeito de surpresa no comercial da Coca-cola citado no início deste trabalho.

Assim, o herói, o gentil, o pacifista e o amável não podem ser representados por imagens de videovigilância: mais que uma dificuldade em digerir a mensagem transmitida, um distanciamento se provoca até por defesa do espectador, que não encontra o sentido naquilo que não revela o risco, papel das câmeras de vigilância no seu cotidiano (completando um aparato que também inclui as grades, cercas elétricas, alarmes etc.).

\section{Discurso e critérios de noticiabilidade}

O que se elege para ser notícia num universo de acontecimentos deve facilmente se vincular ao repertório da audiência, sob pena de, assim não sendo, haver prejuízos no entendimento daquilo que se transmite. Dessa forma, os enquadramentos já levam em conta toda carga de tragicidade que envolve as imagens de videovigilância. Mais que isso, o "o quê" do lide é destacado e, enfim, prevalece sobre os outros elementos "quem", "onde", "quando", "como" e "por quê" são relegados a um segundo plano de importância. 
É por isso que qualquer cena trágica de uma câmera de vigilância pode ganhar destaque a qualquer tempo, pois que os enquadramentos eleitos pelo meio TV tornam o conteúdo novo (reesquentam). Uma vez que esse conteúdo é editado e reenquadrado, o objetivo se torna telejornalístico e, portanto, um fato passível de ser noticiado a qualquer tempo, preenchendo a grade de programação do telejornal, interferindo nos critérios de noticiabilidade e criando uma natural desordem editorial nos discursos formulados e exibidos.

Os estudos sobre Newsmaking também merecem ser recordados nessa análise, uma vez que contribuem para o entendimento das notícias nos modelos que são ofertados à sociedade. Mauro Wolf elenca critérios de noticiabilidade que fazem um acontecimento:

Determina-se, assim, um conjunto de critérios de relevância, que definem a noticiabilidade (newswortthines) de cada evento, ou seja, sua 'aptidão' para ser transformado em notícia [...]. Sendo assim, a noticiabilidade está estritamente ligada aos processos que padronizam e tornam rotineiras as práticas de produção (WOLF, 2003, p. 195).

Sobre o aspecto do enquadramento, pode-se trazer à tona a questão do discurso proposta por Foucault (2010): o discurso será verdadeiro quando assumir as ideias dominantes, quando refletir aspectos históricos com os quais se possa identificar e, dentre outras coisas, quando puder legitimar técnicas e saberes relacionados a uma disciplina. Ainda, existe a relação em se revelar e se esconder algo com o intuito de se estabelecer uma relação de poder: dominar sujeitos a partir de um ponto de vista (FOUCAULT, 2010, p. 9-10). Nesse sentido, um comportamento decorre do telespectador que pressupõe uma dominação sobre seu olhar.

A construção e a credibilidade de uma notícia estão intimamente relacionadas à impressão que o discurso proferido causa nas audiências. Os critérios de seleção de palavras e de relativização dos meios e do público que irá recepcionar essa informação são considerados pelos agentes noticiosos, porquanto precisam denotar consonância com diretrizes e paradigmas incorporados pelos grupos a que se destina a mensagem (BERGER; LUCKMAN, 2003, p. 101-102). O discurso verdadeiro, por assim dizer, é o discurso relativizado para os diversos contextos e interesses que envolvem a organização de símbolos, códigos e linguagens cujo entendimento é formalizado através da reciprocidade - ou negação - ao que é apropriado pelo grupo a que se designa (FOUCAULT, 2010). 
Em um sentido bastante amplo, o discurso pretende levar alguma mensagem, seja enunciativa, seja explicativa, como uma forma de informar algo àqueles que dão atenção ao que se é passado por meio do discurso. Além disso, o que se profere ou se expõe pretende ser inteligível, do contrário não haveria propósito na própria ação.

Diante desse cenário, na grande arena midiática em que se estabelece um jogo de enunciados protagonizado pelo telejornalismo tratando de imagens de vídeovigilância, pode-se também recorrer às análises propostas por Goffman (2002) sobre plateia/bastidores: concebe-se um acordo tácito entre o que será apresentado por aqueles que estão atrás dos holofotes e a plateia que recepciona essa encenação. Tudo o que é representado, incluindo o ambiente em que a ação é gerada, faz parte de uma expectativa, uma confiança, uma garantia de que o "espetácuIo" não mostra nenhuma surpresa. Como em uma zona de conforto, em que as condições e os elementos dispostos são esperados, gerando uma posição de segurança, os papéis são desempenhados a fim de estabelecer uma condição, seja pela posição ocupada, seja pelo que se pretende alcançar junto à audiência, para a legitimidade da encenação.

Isso acontece, por exemplo, quando se pretende exaltar sentimentos de repulsa a um assassino ao se apelar para o choque resultante das cenas de violência explícita. Anteriormente, havia um acordo tácito, tendo em vista que o assassino deveria ser condenado pelo seu crime. Agora, toda sanha da audiência se materializa no enquadramento das cenas do ocorrido capturadas pelas câmeras de vigilância, chegando ao ponto do grotesco se fazer (o trágico chegando às vias de fato), logo o público não espera outra coisa que não seja a condenação pública por meio de matérias jornalísticas que confirmem essa posição. Consequentemente, a exaltação, os sentimentos e os comentários gerados acabam por autenticar o discurso como eficaz, tendo em vista que a sua enunciação ocorreu no momento em que as expectativas pela sua divulgação foram alcançadas.

Sobre a relatividade do discurso, considerando a sua condição de verdadeiro ou falso, é fundamental abordar o conceito de comentário proposto por Michel Foucault (2010). O comentário acerca do discurso contribui para que este permaneça relevante através dos tempos. A compreensão do discurso se dá por sua capacidade de permanecer vivo e constantemente relembrado por aqueles que o adotaram. $\mathrm{O}$ comentário renova a posição do discurso e a possibilidade de enxergar o que ainda pode ser dito e, portanto, apropriado continuamente. 
É assim que as mesmas imagens de videovigilância estão continuamente retornando à tela, uma vez que são suítes mais do que válidas para servirem de artifício para outras narrativas de temáticas afins - ou mesmo servirem de matéria-prima para outras reportagens. A referência mantém o discurso "apropriável", pois dá margem para que incorporações mais recentes possam ser feitas. Consequentemente, o discurso permanece inteligível.

De toda forma, a notícia constituída a partir de imagens de câmeras de vigilância está em acordo com o que a audiência acredita ser autêntico, se conecta ao desejo de verdade do cidadão embutido no telespectador que espera que o Jornalismo cumpra com seu papel. A avaliação do processo de newsmaking na construção da credibilidade jornalística delineia as ações que envolvem a produção de um discurso dito verdadeiro. A propriedade do discurso está relacionada à necessidade de poder e ao desejo (FOUCAULT, 2010, p. 10) e em como símbolos, códigos e linguagens podem ser marcados em busca de objetivos e esclarecimentos previamente determinados.

Desse modo, esse processo é consolidado à medida que hierarquiza contextos e posicionamentos assumidos nas representações sociais. Um discurso é formalizado a partir da interligação das descontinuidades que promovem a sua existência (FOUCAULT, 1987, p. 61-62). Por isso, pode-se falar em um discurso histórico, o qual não envolve, necessariamente, uma cronologia linear, mas a dualidade entre o que se afirma e o que se deve negar oportunamente. Ainda, cabe ressaltar o discurso que engloba as especificidades inerentes às coisas que não podem ser categorizadas em disciplinas, mas que, ainda assim, revelam um discurso assumido a partir de padrões comportamentais.

A construção social da sociedade, portanto, deriva da constituição de uma linguagem que será repetida enquanto permanecer inteligível para um agrupamento e funcionará como um referencial, preso a tradições históricas, que formalizará uma identidade e um pertencimento (BERGER; LUCKMAN, 2003, p. 116). Nesse sentido, Leonel Aguiar (2007) ao analisar os critérios de noticiabilidade, contribui para o entendimento de como as empresas jornalísticas elegem um determinado acontecimento como noticiável:

Pela teoria do newsmaking, o jornalismo é um dispositivo de construção da realidade; logo, não pode ser mero reflexo do real. Ou seja, as notícias - e também as reportagens - não refletem os acontecimentos que se dão a ver, mas são antes de tudo construções narrativas que produzem 
condições de possibilidades através das quais a realidade se dá a conhecer. A noticiabilidade é constituída pelo conjunto de requisitos que se exige dos acontecimentos - tanto do ponto de vista da estrutura do trabalho nos jornais como também do profissionalismo dos jornalistas - para que possam adquirir a existência pública na formação discursiva denominada notícia. Qualquer acontecimento que não possua esses requisitos é excluído, por não ser adequado às rotinas produtivas e às normas da cultura profissional (AGUIAR, 2007, p. 6).

Aguiar também destaca outro critério de noticiabilidade referente aos meios de comunicação: outra forma de eleição de notícias seria a frequência relacionada ao lapso de tempo necessário para que um acontecimento tome forma e adquira significado. Quanto mais a frequência do acontecimento se assemelhar à frequência do meio de informação, mais provável será a sua seleção como notícia (AGUIAR, 2007).

\section{A estética da tragicidade: câmera flagra assassinato}

Nessa altura das reflexões deste trabalho, torna-se fecunda a análise de um caso específico de uso de imagens de videovigilância com a finalidade de se verificar a ocorrência dos conceitos aqui elencados.

Foi escolhido um exemplo que reunisse em si aspectos ricos o suficiente para que as proposições (em toda a sua extensão) pudessem comparecer no corpus observado. Assim, a matéria telejornalística em questão trata do assassinato de uma mulher aposentada durante um suposto assalto dentro de sua própria casa ${ }^{4}$.

Como primeiro aspecto a ser destacado, o caso normalmente não ganharia espaço em telejornais de rede nacional, dado que trata de um fato isolado, mas principalmente porque o fato se desenrolou no Município de Pavão, Vale do Mucuri, interior do estado de Minas Gerais, ou seja, fora dos grandes centros metropolitanos; normalmente, dá-se destaque para as praças do Rio de Janeiro, São Paulo e Brasília, nos quais regularmente ocorrem os grandes acontecimentos que despertam a atenção da mídia e que cumprem os requisitos básicos para garantir a audiência no âmbito do país. Foi porque existiam imagens registradas por uma câmera de segurança, instalada por ordem da própria vítima no local do crime,

4 Para assistir, acessar: <http://globotv.globo.com/rede-globo/jornal-hoje/v/camera-flagra-assassinato-de-aposentada-durante-assalto-dentro-de-casa/2059635>. 
que a pauta ganhou valor e enquadramento na grade de programação do Jornal Hoje da Rede Globo de Televisão.

Outro ponto que chama a atenção é o fato de o crime ter ocorrido no dia 14 de junho de 2012 e ter sido noticiado apenas em 26 de julho seguinte. Essa informação é olvidada pela reportagem, o que transmite a sensação de que se trata de assunto novo. $O$ "quando" não comparece na narrativa e, efetivamente, o "o quê" é superexaltado, esmaecendo os outros elementos do lide que aparecem apenas superficialmente, a mero título de "liga" da costura empreendida.

A reprodução da imagem da câmera de vigilância em si, tal como é próprio da representação figurativa desse tipo de aparato tecnológico, exibe a cena por ponto de vista específico, em perspectiva de cima para baixo, com contorno grande-angular, e profundidade estendida. Não há definição de cores, apenas um tom sépia que garante um efeito de verdade aos instantes reproduzidos. Em verdade, a estética das imagens de videovigilância já expurgou de sua significação qualquer percepção de encenação, produção ou artificialidade. Há um contrato simbólico que atribui um senso de "documento" ou "prova" a esse tipo de imagem inclusive é essa premissa que atribui caráter preventivo às câmeras de vigilância: inibem a ocorrência de crimes ou infrações porque o marginal se ressente da possibilidade de incriminação irrefutável (a menos que a câmera esteja camuflada, como ocorre muito em situações em que famílias vigiam empregados, por exemplo).

Praticamente toda a matéria retratada é feita a partir da cobertura das imagens pela narração do próprio apresentador (nota coberta). Esse formato de exibição revela a possibilidade de enxugamento dos quadros de equipes jornalísticas, pois bastavam as imagens capturadas pelo cinegrafista - que não tem a função de apurar, escrever e formatar, como ocorre com o repórter in loco - para ilustrar o produto noticioso. Mais ainda, só as câmeras de vigilância já dariam conta da parte visual de toda a reportagem.

A narração, a propósito, desconecta-se do tom próprio utilizado normalmente pelo apresentador quando da ancoragem do telejornal em questão, para assumir um tom bem mais grave e interpretativo, quase que teatral, de modo que a cena ganhe sentido espetacular no áudio tanto quanto requer o "peso" da imagem. A cena muito forte, que testemunha um assassinato à queima-roupa, implica que a locução se equipare em termos trágicos ao que a imagem revela.

Outro quesito que merece observação é o uso de recursos gráficos em trechos específicos da cena. Discos que reforçam o contraste (claro/ 
escuro) destacam pedaços significativos da imagem, determinantes para a visualização do que se narra, e conduzem os olhos do espectador para sobre os elementos eleitos para a costura sintática do discurso. Esse subterfúgio ainda serve para completar simbolicamente as lacunas que a imagem distorcida e de pouca qualidade não consegue revelar em detalhes.

Decupando-se todos os aspectos elencados neste artigo, pode-se reconhecer os conceitos aludidos anteriormente. Mas, finalmente, o auge dessa observação encontra-se na certeza de que todos (ou pelo menos a maioria) dos quadros telejornalísticos contemporâneos poderiam ser alvos das mesmas análises. A hipótese inicial, de que todas as cenas de videovigilância parecem compor uma única narrativa, como se uma continuasse a outra, para se efetivar, precisava da identificação dos mesmos efeitos de presença (LANDOWSKI, 2002) em qualquer exemplo analisável - tal qual parece ocorrer.

\section{Considerações finais}

Assim se constrói o telejornalismo apócrifo: agendado e embasado pela imagem cedida pela família da vítima, a tragicidade inerente à videovigilância coloca esse tipo de narrativa no ar diariamente. Miquel Alsina (2009) colabora para a discussão dessa análise ao elencar elementos essenciais do acontecimento e discutir o jornalismo como uma atividade especializada da construção da realidade social. $O$ autor trabalha com a efetividade do discurso jornalístico em um processo que além de informar, faz crer (persuadir), agir (manipular) e sentir (emocionar) - bastante pertinente para se pensar na mídia explorando situações de risco diante de um público ávido por consumir a tragicidade que transborda das imagens de câmeras de segurança.

Ainda, o telejornalismo apócrifo transforma-se em mais um elemento de inspiração para se investigar os desafios impostos à atividade jornalística no mundo contemporâneo, dada a circulação excessiva e flutuante de informações num cenário digital que obriga o jornalista a repensar o seu papel e a sua forma de atuação no processo produtivo, sobretudo nos telejornais. Edna de Melo Silva e Liana Vidigal Rocha (2010), ao analisarem o telejornalismo na convergência de tecnologia de informação, destacam:

O jornalismo televisivo precisou rever as rotinas de produção para tornar seu noticiário mais atrativo para um telespectador que já poderia ter visto a notícia em tempo real, através de sítios noticiosos. [...] a internet 
ANDRADE, A. P. G. de.; AZEVEDO, S. T. de.

se torna ao mesmo tempo aliada e concorrente, uma vez que facilita a pesquisa de fontes novas, porém disputa audiência (SILVA; ROCHA, 2010, p. 198).

As imagens chamadas apócrifas já fazem parte da realidade construída pelo imaginário do público espectador. Essa prerrogativa é o que viabiliza que as imagens apócrifas sejam acionadas pelos telejornais como objetos naturais de composição de narrativas a serem veiculadas.

\section{Referências}

ALSINA, M. R. A construção da notícia. Petrópolis: Vozes, 2009.

ANDRADE, A. P. G. Telejornalismo apócrifo: imagens de câmeras de vigilância e vídeos amadores na construção da narrativa telejornalística. In: CONGRESSO BRASILEIRO DE CIÊNCIAS DA COMUNICAÇÃO, 33, 2010, Caxias do Sul. Anais... São Paulo: INTERCOM, 2010.

ANDRADE, A. P. G; AZEVEDO, S. T. Eu agendo, tu agendas: a construção da notícia através do telejornalismo apócrifo. In: ENCONTRO NACIONAL DE PESQUISADORES EM JORNALISMO, 9, 2011, Rio de Janeiro. Anais... Rio de Janeiro, 2011. CD-Rom.

ANDRADE, A. P. G; AZEVEDO, S. T. Imagens cedidas e a narrativa jornalística na TV: o telejornalismo apócrifo e a dupla performance. In: ENCONTRO NACIONAL DE PESQUISADORES EM JORNALISMO, 8, 2010, São Luís. Anais... São Luís, 2010. CD-Rom.

AGUIAR, L. Ensinar as práticas a partir da teoria do jornalismo: uma proposta pedagógica. In: ENCONTRO NACIONAL DE PROFESSORES DE JORNALISMO, 10, 2007, Goiânia. Anais... Goiânia, 2007. Disponível em: <http://www.fnpj.org.br/soac/ocs/ viewpaper.php?id=42\&cf=1>. Acesso em: 15 mar. 2013.

BERGER, P.; LUCKMANN, T. A construção social da realidade. Petrópolis: Vozes, 2003.

BARRETO, R. M. Criatividade em propaganda. 12 ed. São Paulo: Summus, 2004.

FOUCAULT, M. A arqueologia do saber. Rio de Janeiro: Ed. Forense Universitária, 1987.

FOUCAULT, M. A Ordem do discurso. São Paulo: Loyola, 2010.

GOFFMAN, E. A representação do eu na vida cotidiana. Petrópolis: Ed. Vozes, 2002. 
LANDOWSKI, Eric. Presenças do outro: ensaios de sociossemiótica. São Paulo: Perspectiva, 2002.

SILVA, E. M.; ROCHA, L. V. Telejornalismo e ciberespaço: convergência de tecnologias e informação. In: VIZEU, A.; PORCELLO, F.; COUTINHO, I. (Org.). 60 anos de Telejornalismo no Brasil: história, análise e crítica. Florianópolis: Insular, 2010. p. 197-214.

VAZ, P. Corpo e risco. In: VILLAÇA, N.; GÓES, F.; KOZOVSKI, E. (Org.). Que corpo é esse? Rio de Janeiro: Mauad, 1999.

WOLF, M. Teorias da comunicação. Lisboa: Presença, 2003.

Recebido: 27/01/2013

Received: 01/27/2013

Aprovado: $24 / 02 / 2013$

Approved: 02/24/2013 